\title{
Epidemiology and treatment of canine mammary tumours in Jammu region of India
}

\begin{abstract}
The study was carried out on canine cases referred to the department of Surgery and Radiology with the history of enlargement of one or more mammary glands (from last three months to two years). The incidence of mammary tumours was $24 \%$ (12 out of 50 ) among the different tumours and $0.48 \%$ among all canine cases. The affected animals were aged 5-13 years with a mean value of $9.1 \pm 0.64$ years. The malignant tumours accounted $41.66 \%$ of the mammary tumours. The metastasis lesions in the form of multiple soft tissue nodules were observed in the lungs of only three of the five malignant tumours. Surgery being the mainstay of the management for canine mammary tumours, simple or regional mastectomy was performed in all cases in the present study. All the animals had uneventful recovery and sutures were removed without any complication of wound. However, long term follow up for 3-11 months revealed that two of the animals with adenocarcinoma and one animal with myoepithelioma died.
\end{abstract}

Keywords: neoplasm, mammary tumor, malignant
Volume 7 Issue 2 - 2018

\author{
Neha Sharma,' Ajay K Gupta,' Riyaz A Bhat,' \\ Mohd 'Yatoo, ${ }^{2}$ Oveas R Parray' \\ 'Department of Veterinary Surgery and Radiology, India \\ ${ }^{2}$ Division of Veterinary Medicine, SKUAST-K, India
}

Correspondence: Neha Sharma, Department of Veterinary Surgery and Radiology, Faculty of Veterinary Sciences \& Anima Husbandry, SKUAST-J, R. S. Pura, Jammu, India, 181102 ,

Email sharmanehavet@gmail.com

Received: March 01, 2018 | Published: April 12, 2018

\section{Introduction}

Most of the animals are living to an older age due to advances in veterinary healthcare. Cancer has now emerged as leading cause of pet animal deaths. ${ }^{1}$ Neoplastic conditions are common in geriatric dogs and $6-30 \%$ of the dogs with a mean age of 5-10 years are commonly affected. ${ }^{2}$ According to the American Veterinary Medical Association, cancer causes almost $50 \%$ of deaths in pets over the age of 10 years. Mammary gland tumours rank second as the most common neoplasms in dogs after skin tumours, ${ }^{3}$ however, it represents the most common malignant tumour in the female dogs and certain breeds appear to display an increased cancer predisposition. ${ }^{4}$ The incidence of mammary tumours in entire bitches is approximately $71 \%,{ }^{5}$ whereas it accounts for approximately $50 \%$ of all tumours in female dogs and $82 \%$ of the tumours of the female sex organs. ${ }^{6}$ Different types of cancer can behave very differently. They grow at different rates and respond to different treatments. That is why dogs with cancer need treatment that is aimed at their particular kind of cancer. Because we do not yet know what causes most cancers, it is not known how to prevent them. Complete surgical removal of localized cancer that has not spread cures more patients (human and animals) than any other form of treatment. ${ }^{7}$ A cancer that spreads only to local lymph nodes may still be cured if all the involved nodes can be removed along with the primary tumour. Surgical treatment of malignant neoplasms has limitations and often is unsatisfactory, although even when a cancer is widespread, removing a bleeding or infected mass, or simply a large one that is interfering with a normal physical function, can provide relief and temporarily improve the quality of life. The ultimate fate of many patients does not rest with the surgeons's skill, but with the biological behavior of the neoplasm. Many malignancies are beyond treatment when first diagnosed. Chemotherapy is used to prevent and control the metastatic spread of cancer cells. However, most canine cancers are only moderately sensitive to chemotherapy. It can cure only one type of cancer in dogs: transmissible venereal tumours. When used as the only form of treatment, chemotherapy usually does not extend survival, lymphosarcoma and leukemia are exceptions. Radiation therapy is used primarily for local tumours that have not metastasized. Many canine tumours are sensitive to radiation. They include mast cell tumours, transmissible venereal tumours, squamous cell carcinomas, cancers of the oral and nasal cavities, and soft tissue sarcomas. A potential disadvantage of radiation therapy is that it not readily available as it requires special equipment and must be done at referral veterinary centers. Other treatment options include cryotherapy, hyperthermy, photodynamic therapy, diet modification, immunotherapy, hormone therapy and non steroidal anti-inflammatory drug therapy etc. The present study was aimed to know the mammary tumours epidemiology and its treatment.

\section{Materials and methods}

The present study was carried out on dogs which were presented at the Teaching Veterinary Clinical Complex (TVCC) of SKUASTJammu for a period of one year. Complete history of the dogs suspected for neoplasia was recorded and clinical examination comprising of observation, palpation, percussion, recording of physiological parameters was performed. The consistency of visible growth or swelling, if any, their size, their attachment to the skin and the tissues underneath, whether ulcerated or not, engorgement of the blood vessels and lymphatic's draining the affected area etc. were recorded. The tumours were diagnosed on the basis of histopathological and cytological studies after representative tissue pieces were collected from multiple (at least 3 ) sites in tumour suspected cases and fixed in $10 \%$ neutral buffered formalin followed by processing of the sample and then histopathological studies. Radiograph of the region involved, chest and abdomen were performed to know the extent of the lesion and to find out the metastatic lesions (Figure1), (Figure 2). Ultrasonography (USG) of the growth/swelling was performed to record the echo texture, blood supply, invasion of the surrounding tissues and whether cystic or solid. USG of abdomen was performed to find out metastatic lesions in the liver, lymph nodes, peritoneum and other visceral organs. All the cases of mammary gland tumours were managed by performing mastectomy as per method described by. ${ }^{8}$ One gland (simple mastectomy), or several glands (regional mastectomy) were excised depending on the number of mammary 
glands involved. Ovariohysterectomy $(\mathrm{OVH})$ was performed before performing mastectomy in those intact bitches where the owners gave their consent. An elliptical incision through skin and subcutaneous tissue was made around the involved mammary gland(s). The tumour along with the gland was separated from the abdominal or thoracic muscles by blunt dissection with fingers and scissors. The bleeders, and in most of the cases, caudal superficial epigastria vessels were ligated with 3-0 polyglycolic acid (I-col, Stericat Gutstrings (P) Ltd., Gurgaon, India). Ipsilateral inguinal lymph node was also removed whenever the inguinal mammary gland was affected. Superficial epigastric vessels were also ligated in a few cases. The wound was lavaged with normal saline. The dead space was obliterated by applying subcutaneous walking sutures in simple continuous pattern using 1-0 polyglycolic acid. The skin incision was closed with simple interrupted suture and abdominal bandaging was performed to apply some pressure over the surgical site and to prevent self mutilation. Lumpectomy/partial mastectomy or chain mastectomy was not performed in any of the cases.

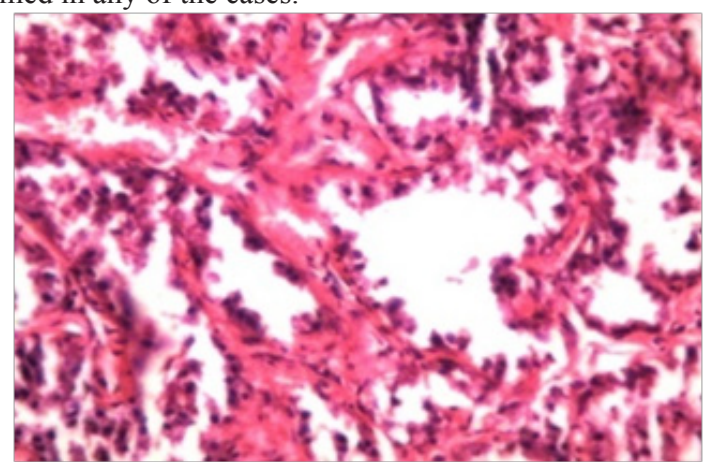

Figure I HP of Mammary adenocarcinoma showing ducts partially occluded with in growth of tumour cells and presence of extensive fibrous stroma.

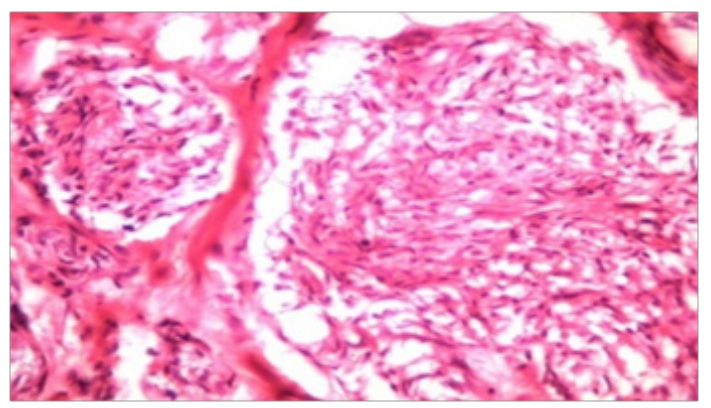

Figure 2 HP of Mammary adenocarcinoma (pappilary form) showing papillary projections in the acinar lumen with pleomorphic and anaplastic cells and presence of mitotic figures.

\section{Results and discussion}

In the present study, the incidence of mammary tumours was quiet high, $24 \%$ (12 out of 50 ) of all tumours and $0.48 \%$ of all canine cases. This finding was in agreement with many workers, ${ }^{9-12}$ who have also reported that mammary gland tumours were common in dogs and represented the most common neoplasms in sexually intact bitches. However, Arnesen et al. ${ }^{13}$ reported comparatively lower prevalence of mammary tumours, $13 \%$ of the total neoplasm in dogs, and all the cases were recorded in intact females. The affected animals were aged 9.1 \pm 0.64 (5-13) years. This finding is in agreement with the findings of Moulton, ${ }^{14}$ Alanza et al,. ${ }^{15}$ Egenvall et al. ${ }^{11}$ who reported that mammary tumours were extremely rare in dogs younger than five years of age and that the incidence increased sharply at approx. six years of age and incidence peaked at about 8-12 years of age. Fourth and fifth glands were the most affected in the present study in agreement with Muligan ${ }^{16}$ and Moulton ${ }^{14}$ who also reported that $60 \%$ of mammary tumours occurred in the posterior glands. The malignant tumours formed $41.66 \%$ of the mammary tumours, in agreement with the findings of Brearley ${ }^{17}$ who reported that $40 \%$ mammary tumours were malignant and Rutteman et al. ${ }^{18}$ and Misdorp ${ }^{19}$ who also reported that $41-53 \%$ of mammary tumours were malignant. However, Gill, Veena et al. ${ }^{20}$ and Gupta et al. ${ }^{21}$ reported very high incidence (75-96\%) of malignant mammary tumours in dogs. The benign and malignant tumours could not be differentiated based on clinical examination or on ultrasonography, as some of the tumours with firm attachment to the skin and underlying tissues and those with heterogenous echo texture mixed with anechoic cavities were both benign as well as malignant. However, all the mammary tumours having homogenous echo texture on USG were benign. This finding corroborates the finding of Veena et al. ${ }^{20}$ who reported that all benign tumours had homogenous echogenicity and some had anechoic cystic cavities. The metastasic lesions in the form of multiple soft tissue nodules were observed in the lungs of only three of the five malignant tumours (Figure 3). Owen ${ }^{22}$ and Klopfleisch et al. ${ }^{23}$ have also reported that metastasis of mammary tumor in dogs was frequently found in the regional lymph nodes and lungs. Gupta et al. ${ }^{21}$ have reported metastatic lung lesions in the form of nodular pattern, milliari pattern, alveolar pattern, mixed interstitial and bronchial pattern. No metastatic lesion was visible in abdominal viscera on USG in agreement with Gupta et al. ${ }^{21}$ The reason for not detecting metastatic lesions in lungs in all cases of malignant tumours might be the fact that lesions less than $0.5-1.0 \mathrm{~cm}$ in size may not be visible on radiographs. ${ }^{24}$

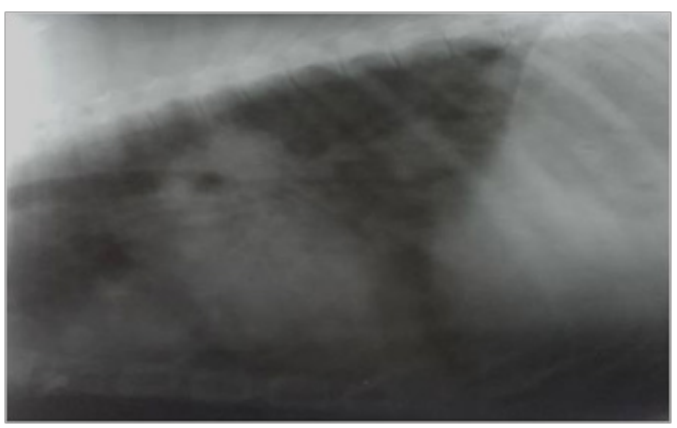

Figure 3 Mammary adenocarcinoma: Lateral thoracic radiograph showing metastatic lung lesions: Multiple nodular soft tissue densities through out the lungs

Surgery being the mainstay of the management for canine mammary tumours, simple or regional mastectomy (Figure 4), (Figure 5), (Figure 6) was performed in all cases in the present study and chemotherapy was not used because the results have, historically, been disappointing. ${ }^{26}$ Simon et al. ${ }^{27}$ reported that although dogs treated with chemotherapy had a tendency toward higher long-term local control and survival rate but there was no significant difference in the recurrence free interval, time to metastasis and overall survival with surgery alone or in combination with adjuvant chemotherapy. Gupta et al. ${ }^{21}$ also did not find significant difference in the mean survival time and survival rate between the dogs treated by surgery alone or surgery followed by chemotherapy. Low rate of death (reported in three animals) and recurrence (noticed in one case) during the study period might be due to the fact that the post operative period of follow 
up of only 3-12 months was less, as Bostock ${ }^{28-32}$ reported that animals with benign tumours had mean survival time of at least 114 weeks and those with malignant tumours survived for 70 weeks. Currently there is no surety way to prevent mammary tumours in dogs but several things may help to reduce that risk. Among them, spaying a bitch before her first heat cycle is strongly protective against breast cancers in canines. Some authorities recommend not to bred females with history of mammary tumours as it may have hereditary association.

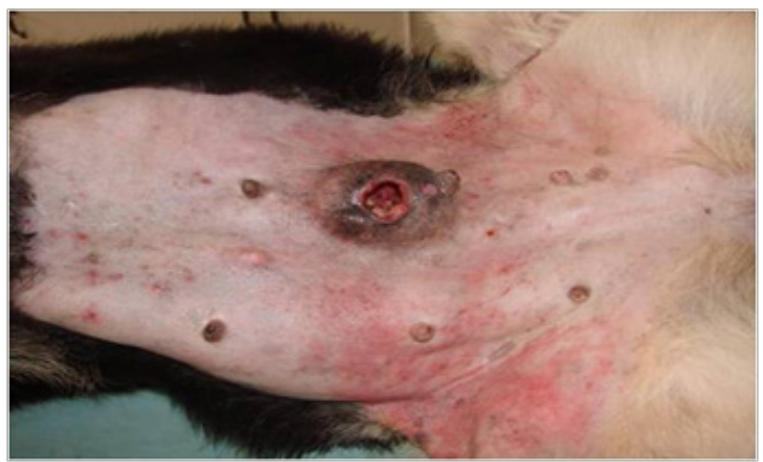

Figure 4 Mammary adenocarcinoma: The ulcerated tumour of left cauda abdominal gland is firmly adherent to the skin and underlying tissues.

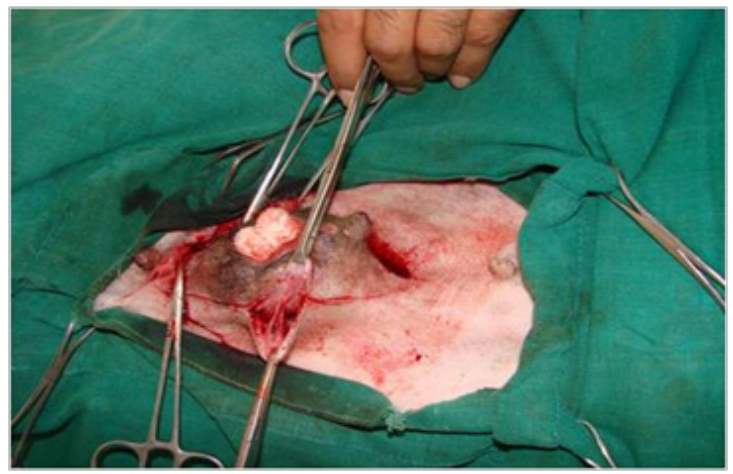

Figure 5 Mammary adenocarcinoma: Mastectomy being performed. The tumour was firmly attached to the skin and underlying tissues

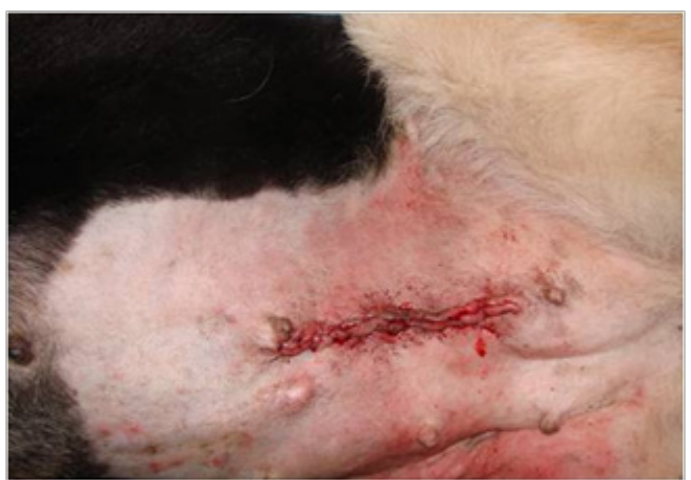

Figure 6 Mammary adenocarcinoma:The animal after mastectomy and skin suturing

\section{Conclusions}

The incidence of mammary tumours is $24 \%$ in the dogs of Jammu region. The affected animals are usually around 9 years of age. The malignant tumours form $41.66 \%$ of the mammary tumours. Surgery is the mainstay of the management for canine mammary tumours, simple or regional mastectomy was performed in all cases in the present study. The animals have uneventful recovery any complication of wound after surgical removal of mammary tumor. (However, long term follow up for 3-11 months revealed that two of the animals with adenocarcinoma and one animal with myoepithelioma died).

\section{Acknowledgement}

None.

\section{Conflicts of interest}

None.

\section{References}

1. Withrow SJ. Why worry about cancer in pets. In: Withrow SJ, MacEwen EG, editors. $3^{\text {rd }}$ edn. Small Animal Clinical Oncology, Saunders, Philadelphia: Elseveier; 2001.

2. Tiley P, Smith FWK. In: Cann C, Vonderhor editors. The five minute vet consultant, 1997. p. 794-795.

3. Moulton JE. Tumours in Domestic animals. $2^{\text {nd }}$ edn. University of California Press, Berkeley and Los Angeles: London; 1978. p. 59-62.

4. Priester WA, Mckay FW. The occurrence of tumours in domestic animals. Natl Cancer Inst Monogr. 1980;(54):1-210.

5. Benjamin SA, Lee AC, Saunders WJ. Classification and behaviour of canine mammary epithelial neoplasms based on life-span observations in beagles. Veterinary Pathology, 1999;36(5):423-436.

6. Ettinger SJ, Feldman EC. Text book of veterinary internal medicine of dogs and cats. $4^{\text {th }}$ edn. WB Saunders: Philadelphia; 1995. 1702. p.

7. Chabner BA, curt GA, Hubbard SM. Surgical onchology research development: The perspective of the National cancer institute. Cancer Treatment Report. 1984;68(6):825-829.

8. Fossum TW, Dewey CW, Horn CV, et al. Small Animal Surgery. $4^{\text {th }}$ edn Mosby. Elsevier: Missouri: 2013

9. Moe L. Population-based incidence of mammary tumours in some dog breeds. J Reprod Fertil Suppl, 2001;57:439-443.

10. Dobson JM, Samuel S, Milstein H, et al. Canine neoplasia in the UK.Estimates of incidence rates from a population of insured dogs. $J$ Small Anim Pract. 2002;43(6):240-246.

11. Egenvall A, Bonnett BN, Ohagen P, et al. Incidence of and survival after mammary tumours in a population of over 80,000 insured female dogs in Sweden. Prev Vet Med. 2005;69(1):109-127.

12. Brønden LB, Nielsen SS, Toft N, et al. Data from the Danish veterinary cancer registry on the occurrence and distribution of neoplasms in dogs in Denmark. Vet Rec. 2010;166(19):586-590.

13. Arnesen K, Gamlem H, Glattre E, et al. The Norwegian canine cancer register 1990-1998. Report from the project "Cancer in the Dog". European Journal of Companion Animal Practice. 2001;11(2):159-169.

14. Moulton JE. Tumours in domestic animals. In: Moulton, JE editor. $4^{\text {th }}$ edn University of California press: loss angels; 1990. p. 518-552.

15. Perez Alenza MD, Peña L, del Castillo N, et al. Factors influencing the incidence and prognosis of canine mammary tumours. J Small Anim Pract. 2000;41(7):287-291.

16. Mulligan RM. Mammary cancer in the dog, a study of 120 cases. Am J Vet Res. 1975;36(9):1391-1396.

17. Brearley MJ. Mammary gland tumours in the dog. In Practice. 1989;11(6):248-253. 
18. Rutteman GR, Withrow SJ, MacEwen EG. Tumors of the mammary gland. In: Withrow JS, Vail DM, Page RL editors. Withrow and Maceven's Small

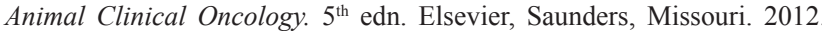
$768 \mathrm{p}$.

19. Misdrop W. Tumours in Domestic Animals. In: Mueten DJ, editor. $4^{\text {th }}$ edn. Iowa state press: Blackwell Publishing company; 2002. 109 p.

20. Veena P, Kumar RVS, Raghavender KBP, et al. Ultrasonographic imaging of canine mammary tumours. Indian Veterinary Journal, 2001;88(11):2324.

21. Gupta P, Raghunath M, Gupta AK, et al. Clinical study for diagnosis and treatment of canine mammary neoplasms (CMNs) using different modalities. Indian Journal of Animal Research. 2014;48(1):45-49.

22. Owen LN. A comparative study of canine and human breast cancer. Invest Cell Patho.1979;2(4):257-275.

23. Klopfleisch R, Gruber AD. Increased expression of BRCA2 and RAD51 in lymph node metastases of canine mammary adenocarcinomas. Vet Pathol. 2009;46(3):416-422.

24. Kealy J K, Mc Allister H. Bones and joints. Diagnostic radiology and ultrasonography of the dog and cat. $4^{\text {th }}$ edn. WB Saunders: Elsevier; 2004.528.p.
25. Ferguson HR. Canine mammary gland tumours. Vet Clin North Am Small Anim Pract.1985;15(3):50-511.

26. Polton G. Mammary tumours in dogs. Irish Veterinary Journal, 2009;62(1):50.

27. Simon D, Schoenrock D, Baumgärtner W, et al. Postoperative adjuvant treatment of invasive malignant mammary gland tumours in dogs with doxorubicin and docetaxel. J Vet Intern Med. 2006;20(5):1184-1190.

28. Bostock DE. The prognosis following the surgical excision of canine mammary neoplasms. Eur J Cancer. 1975;11(6):389-396.

29. Misdrop W, Hart AA. Prognostic factors in canine mammary cancer. J Natl Cancer Inst. 1976;56(4):779-786.

30. Bergman PJ, Kent MS, Farese JP. Melanoma. In: Withrow JS, Vail DM, editors. Withrow and Maceven's Small Animal Clinical Oncology. $5^{\text {th }}$ edn. Elsevier: Saunders; 2013. 322. p.

31. Uehlinger P, Glaus T, Hauser B, et al. Differential diagnosis ofhypercalcemia-a retrospective study of 46 dogs. Schweiz Arch Tierheilkd 1998;140(5):188-197.

32. Elliott J, Dobson JM, Dunn JK, et al. Hypercalcemia in the dog.A study of 40 cases. Journal of Small Animal Practise.1991;32:564-567. 